\title{
Environmental tolerances and visitor preferences for some forest recreation habitats in British Columbia
}

J. HARRY G. SMITH

Faculty of Forestry, University of British Columbia, Vancouver, B.C.

J. RUSSEL MATTHEWS

F. F. Slaney and Co. Ltd., Vancouver, B.C.

Les tolérances de l'environnement et les préférences des visiteurs pour quelques endroits récréatifs dans les forêts de la Colombie Britannique. L'auteur décrit les résultats de quelques études préliminaires concernant les préférences des visiteurs ainsi que les capacités de transport vis-à-vis des parcs de la Colombie Britannique et de quelques parcs montagnards de l'Alberta. On y discute l'importance de connaître davantage les besoins du public ainsi que son intérêt récréatif dans l'utilisation des forêts et des régions sauvages. Une attention spéciale est apportée quand aux sources d'information ainsi qu'à certaines régions méritant considération pour de telles études; le tout servant de base en vue d'un aménagement amélioré pour la récréation en plein air. Les problèmes du public sont bien présents et il est évident que les forestiers connaissent beaucoup plus les forêts que les visiteurs. La conclusion suggère qu'une amélioration considérable peut provenir d'un projet sérieux et d'un aménagement modeste conservant la qualité de l'habitat d'autant plus que, la tolérance est élevée pour la plupart des endroits forestiers à vocation récréative dans les régions concernées.

Although we recognize that the days of the "timber beast" are long past, foresters need help in their struggle for understanding and acceptance of their work. As managers of natural resources, foresters "must make every effort to keep knowledge of their publics at the same level, or at a higher level, as knowledge of natural resource management" (Gilbert 1971). We have written this article primarily to draw attention to some research which deserves consideration as the kind of information that should be widely available to foresters and forest recreation managers.

More support is needed for all elements of forest resources research, and recreation deserves a high priority among these. The growing demand for improved recreational opportunities in Canada has not been reflected adequately to date in plans for improved management or expanded research to guide use of either National or Provincial Parks. Even more important to foresters is the fact that recreation on the vast areas of forests and wildlands outside of parks is seldom organized, has little research to guide it, and may be restricted because of conflicting demands.

No Canadian Government agency has provided leadership or sustained financial support to those interested in developing recreation research for forests and wildlands, but this situation may be changing. Research needed to guide development of a full range of outdoor recreation services and opportunities was described by Dooling (1969a) and Kissick (1969). The Science Council of Canada (1970) gave high priority to expansion of research in forest land recreation; Smith and Lessard (1971) drew attention to recreation research needs as a hitherto neg-

${ }^{1}$ Currently undertaking postgraduate work, Bangor, Wales.

lected area. Differences between park and general outdoor recreation needs must be kept in mind.

The increasing concern of people for development of a high quality environment is likely to have a great impact on forest land management in future (Pimlott et al. 1971). Since so much forest recreation is outside of traditional markets, forest managers have few data on what users are willing to pay for services. It is particularly difficult, therefore, to interpret the broad generalities of probable development in terms of what the majority of park users and other participants in forest based recreation really want. There is no doubt at all as to what minority groups are seeking (Littlejohn and Pimlott 1971) but few facts based upon widespread sampling are available to represent the views of the general public. Even when sampling is done the limitations imposed by time, distance, and cost of travel to enjoy outdoor recreation in developed forest environments tend to bias results in favour of those well above average in education and earning power. Views of participants should be compared with those of non-participants.

The Bureau of Outdoor Recreation (1970) described 371 currently active or recently completed outdoor recreation and related environmental research projects. Much information about North American forest recreation obviously is available (Douglass 1969) but more is needed to provide specific solutions to Canadian problems. Solutions will not come easy if the difficulties of investigating and securing support for studies of sound attenuation by tree stands are typical (Matthews 1971). However, awareness of the need to introduce aesthetics into areas traditionally dominated by short-term economic considerations is growing (Smith 1969, Adamovich 1971).

The physical characteristics of forests have been studied for many years but only recently have foresters become painfully aware that we do not live by trees alone. We appreciate Dooling's (1969b) synthesis of the environmental and human elements of carrying capacity as:

The carrying capacity of a recreation site can be thought of as partly dependent on biological and physical factors and partly on what the user considers the desirable recreational experience ought to be.

His definition is in keeping with the Society of American Foresters terminology (Ford-Robertson 1971). Carrying capacity, as used in recreation management in the U.S.A., means the level and type(s) of recreational use that a natural or developed area can provide without deterioration of the quality of the recreational experience or the resource. 
We will not repeat Dooling's (1969b) analysis of the literature on soils, carrying capacity, and resource-based recreation systems, but will discuss three major areas based on British Columbia experience and worthy of study elsewhere in Canada. These are visitor preferences, carrying capacity and standards for use of various habitats, and the potential influences of management on these.

A study of park visitor preferences was made by Apt in 1967 with the cooperation and financial support of the National and Historic Parks Branch of the Department of Indian Affairs and Northern Development of Canada. The Parks Branch of the British Columbia Department of Recreation cooperated in 1967 and again in 1968 when the influences of habitat and management on recreational carrying capacity were being investigated. The 1968 field work was done primarily by D. J. McCallum and by Dr. D. Haley with financial support from a UBC Research grant.

\section{Visitor preferences for forest habitats}

To better understand and serve visitors and potential visitors to forest lands, data are needed as to what they consider important. The limited data available suggest that in 1968 at least $21.3 \%$ of holiday travellers are likely to use and be influenced by forest-based activities (Smith and Lessard 1971). Following a survey of visitor preferences on forest habitat in some mountain parks of British Columbia and Alberta (Apt and Smith 1967) and a thorough interpretation of the results (Apt 1968) we can make some observations as to knowledge of and reaction to various environmental features. Apt personally completed 1,116 questionnaires to record visitor responses to 21 questions which elicited a total of 118 types of answers. Eleven campgrounds of different forest types and of different habitat quality were chosen to provide a potentially large range of visitor preferences within the eight weeks of the peak tourist season in 1967.

Apt (1968) observed that although "there is easily noticeable wind or fire damage in every park along the roadside" $80.6 \%$ of the people interviewed did not see anything unpleasant. Complaints centred on dust, over-crowding, and untidy toilets". A few complained about man-made scars and signs of civilization in the forest. Recently, there have been many strong protests about noise and anti-social behavior (The Sun 1971, Traveller 1971).

Nearly two-thirds of the park visitors were able to recognize tree species, and about the same proportion considered the kind of trees to be important to them. Preferences for particular kinds of forest habitat were weak in comparison with strong desires for certain kinds of camping and special park experiences. "The favourite non-local forest type, the mature Douglas-fir, western hemlock, and western redcedar type of the coast, was preferred by $14.8 \%$ of the visitors."

One third of the visitors had no preference for tree species. Favoured species were lodgepole pine, Douglas-fir, and Engelmann spruce, which usually reflected their actual occurrence in the campgrounds where the interviews were being made. The kind of forest was considered important; $44.3 \%$ favoured large, old trees; $30.0 \%$ liked a mixture of large and small trees; conifers were preferred by $48.9 \%$, and $39.3 \%$ liked mixed forests. Clearings and light mossy or grassy undergrowth were preferred.

Generally speaking, "typical" visitors seem to be about equally enthusiastic for outdoor recreation in virgin forests and in parks of all kinds, with little preference for park ownership or size. It may be significant that Apt actually had to explain terms commonly used to describe human activity in the forest. Managed forests were defined by him as those in which cutting, cleaning, thinning or planting took place. In a virgin forest Apt assumed that only fire prevention is practised. Then "virgin" forests were preferred by $48.5 \%$ and "managed" forests by $41.9 \%$. Wildfalls, burns, dead trees or conks were considered natural and therefore not unpleasant features by $43 \%$ of those interviewed.

Apt (1968) found many significant influences of education and experience on reaction to the factors just discussed, with older and better educated campers generally more discriminating in their interest in and knowledge of the forest.

\section{Carrying capacity and standards}

How much land is needed now and in future depends very much on the ability of habitat to absorb recreational impacts and on the quality of recreational experience visitors expect and are willing to pay for, either directly or indirectly. In his working plan to study recreational capacity of representative B. C. Provincial Parks, McCallum (unpublished data) observed that capacity is a result of the impact of environment on people, the impact of people on that environment, and management procedures which can modify these reciprocal impacts. He sought information as to: $1 /$ how much does natural habitat aid or hinder original allocation, cost of development, cost of maintenance, and cost of improvement or expansion, and 2/ what habitats will provide sustained user satisfaction with minimum investments in facilities and management. For a variety of reasons the objectives of this study, which probably were much too ambitious, were not achieved fully. Nevertheless, some useful observations can be drawn about the relative importance of habitat, public concern for improved habitat, and the role of the manager in providing both.

During the 1960's visits to Provincial Parks in B.C. more than doubled. In 1960, 650 thousand camper nights and 2.45 million day visits were estimated; in 1969 there were an estimated 1.39 million camper nights and 5.63 million day visits (Department of Recreation and Conservation 1970). This degree of park use was supported by about 4,400 campsites and 1,900 picnic tables in 1970 . For all Provincial Parks in B.C., roughly 320 camper nights were provided annually by each developed camp site and roughly 3,100 day visits were assisted by each picnic table available in addition to those associated with individually developed camp sites. 
It is difficult to generalize about standards, but there is considerable agreement that the Provincial Parks of B. C. have been developed and maintained to meet good to excellent standards of quality. The range for developed public campsites in North America is from about 2.5 to 14 units per acre (Bureau of Outdoor Recreation 1967). These standards contrast remarkably with those for which visitors are willing to pay premium prices in the orchards near the beaches of the Okanagan Valley. There, up to 100 campsites per acre may be crowded into "worn out" orchards and up to 200 sites per acre have been "staked" near the most desirable beaches. Although such high-use privately-owned campsites are served by additional public and private lands, supporting areas fall far short of those planned for in public developments. Commonly, the rule of thumb is that for each acre developed for public campsites another 19 are required to provide supporting environment.

Environments in the well managed public campsites of British Columbia are protected additionally by strict limitations of duration of stay, and of use to developed portions, and by closures of gates between $11 \mathrm{pm}$ and $7 \mathrm{am}$. Annual maintenance of campsites and daily servicing during peak use also help to maintain quality. It appears to us as if good design, regular maintenance, and orderly management can do much to establish and continue to offer high quality camping experiences. This is even more true as campsite use by trailers and various kinds of camper units increases; however, large trailers can consume an excessive share of space.

There is no doubt that habitats differ in their ability to withstand use during the peak camping season and to recover from abuse over the next winter. It is our impression that influences of habitat often are minor in relation to the effects of seasonal and periodic variations in climate.

Visitors have an obvious dislike for dirt, mud, dust, flies, and mosquitoes, most of which are subject to amelioration by management. It appears to us that many visitors will accept severe crowding in privately managed campsites to avoid what outdoors enthusiasts consider to be the minor inconveniences of well developed public parks, but further studies of preferences for various kinds of parks are desirable. Visitors have an obvious impact too in their quest for entertainment and fuel immediately adjacent to developed campsites.

In a pictorial record initiated in 1957 by G. D. Taylor, then Geographer of the Provincial Parks Branch of B. C., annual changes to campsites were documented through 1961. Taylor observed in general for the Coastal parks studied by him:

$1 /$ Logs and stumps left on campsite margins fall ready victim to campers with axes.

2/ There is a tendency for all downed trees, branches, etc. to disappear in time.

3 / In areas with light underbrush there is a tendency for the campsite to expand and for areas between campsite and road to be cleared.
4/ Certain types of underbrush such as Oregon grape and fern seem particularly resistant to human erosion.

In planning our studies we saw no need to demonstrate further that "camping was ... detrimental to indigenous vegetation on intensively used areas" (de Vos and Bailey 1970). Such studies are needed locally but we were interested in learning as much as possible about the role of park managers and park designers in establishing and maintaining a high degree of visitor satisfaction for campsites and picnic sites.

Standards for picnicking have been established for two classes of use, family, and group. For good quality family picnicking, standards range between 4 and 8 family units per acre. For group picnicking there may be from 10 to 25 units per acre. A few designers suggest that for picnicking, as for campsites, only about $5 \%$ of the total area be developed for direct visitor use.

McCallum (unpublished report) drew attention to other important elements which affect use within developed areas. In his observations of lower mainland parks he noted that there was lessened site deterioration in areas where beaches or open fields serve to take much of the recreative pressure off the forested areas. "Both the people and the forest prefer ball playing and swimming to axe throwing and engraving". He also suggested that deterioration is in proportion to usage on any particular habitat type and there are definite patterns of camping and preference within individual camping grounds. Management should strive, therefore, to eliminate differential usage rates by improved design and maintenance. When everything else fails a new camping area may be needed.

In a preliminary review of the results of his interviews with users of developed campsites, McCallum found greatest concern for access, and the quality and variety of activities available in parks. Favourable comments exceeded unfavourable by about 4 to 1. After elimination of directly conflicting viewpoints, he ranked the environmental factors of concern to campsite users from high to low as follows: quality of activities, access, variety of activities, kind of habitat, variety of facilities, density of population, naturalness, number of facilities, condition of facilities, and design of the park.

Some of the campsites in the interior of B.C. deteriorate severely in drought years. In 1968 Haley described habitat encountered in Monck Park, north of Nicola Lake. The Park is in a typical dry Montane type with Ponderosa pine and Douglas-fir only on the moister sites. Sparse ground vegetation of sage brush, bunch grass, and many small flowering herbs depends upon annual precipitation of only 10 inches. His impression was that heavy use during July and August leads to real deterioration of sites, resulting in a complete absence of vegetation in camping areas and an acute dust problem. Although there probably are other local examples of over-use the general impression of campsites developed in Provincial Parks in B. C. is good. So far, it appears as if B.C. has avoided situations such as those reported 
by Fradkin and Endicott (1969) with the scare headlines "Population mass destroying U.S. parks" and "Smog, crime take over campsites".

Without careful study it is particularly difficult to discuss the elements that determine whether or not visitors will return to use and enjoy campsites and picnicsites. Effects of site spacing probably should be analysed in addition to numbers of sites per developed acre.

\section{Management potentials}

The role of foresters as resource managers will become increasingly important as population grows, living standards improve, and users become more discerning and demanding. The actual area used in developed campsites is relatively small. Assuming that each campsite required 0.25 acres directly and 4.75 acres indirectly, the roughly 4,400 Provincial campsites in B.C. could be accommodated in 1969 on 22,000 acres. Since there were 275 parks including $6,479,659$ acres in 1969 considerable potentials for expansion remain, but much land must be reserved for enjoyment of park experiences other than camping. During 1971 the number of campsites in the provincial park system was increased to 6,000 as part of a special 15 million dollar program for improvement of park facilities.

Most visitors simply drive through Parks and many of those who stay do so to participate in activities which attract them to the general area among which camping and picnicking are almost incidental. Campsites have become inexpensive roadside bedrooms and it appears as if the job of the recreation manager is to isolate them from excessive road noises (Matthews 1971) and other disturbances. In doing his job the recreation manager is likely to be left increasingly free to use bark and wood chips, gravel, and asphalt to direct traffic and preserve delicate surfaces while holding down dust. Probably, watering and fertilizing of existing vegetation and reseeding would be appreciated by most visitors. Despite the growing interest in nature houses, interpretative trails, and organized tours and study programs, concern for "undisturbed wilderness" appears to be low. This is the impression one has until controversy develops, then supporters rally in defense of wilderness wilder than it was before the white man came. It seems obvious that recreation managers will have to move carefully before and after the peak seasons to make major changes and to retain a low profile during periods of high use.

In most Provincial Parks the crush comes on long weekends in the summer months. In B.C. when the "campsite full" signs go up, disappointed visitors slop over onto unregulated forest lands outside of parks and into already crowded private campgrounds. The contrast between regulated and nonregulated use of forest lands is remarkable and deplorable. The situation may improve in B.C. as a result of the B.C. Forest Service "re-assuming" in 1970 its recreation management role on Crown lands under its jurisdiction (Marshall 1971). Marshall expressed the basic needs and expectations of the majority of forest recreationists as "escape and contrast made possible by convenient access to the forest environment". He saw a need for education to ensure that each individual "understands and respects the forest environment". Some large forest companies and several Tree Farm Licensees also are improving lands under their ownership or control but the basic recreation load still is being carried by B.C.'s Provincial Parks.

B.C. Parks have not yet felt overwhelming pressures of public use because there are more than three acres available per person. This contrasts very favourably with California, for example, which has only .03 acres per person. B.C. park planners have been able to defend their minimum spacing between campsites of 50 vegetated feet very well, so far, and park managers have enjoyed considerable freedom to disturb nature in order to provide essential services to campers and picnickers (J. R. Matthews, unpublished).

\section{Conclusions}

Although British Columbia provincial parks contain signs of deterioration of habitat that are all too familiar to the careful observer and frequent visitor, most users appear well satisfied with them. Natural habitats in British Columbia, with the exception of fragile mountain meadows, are remarkably tolerant of visitor use for camping and picnicking. Tolerance may result from the generally moist climate, short season of intense use, good design and controls of over-crowding, regular care, and reasonable schedule of maintenance and improvements.

Benefits could be derived from higher inputs in the form of dust control on roads and sprinkling of vegetation on heavily used areas, especially in dry regions.

The general impression gained from a 1967 survey of visitor preferences in mountain parks of Alberta and British Columbia is that most visitors have only modest concern for, and limited knowledge of, tree species and other habitat elements which mean much to foresters.

It is obvious that foresters know much about their trees but little about the people who come to enjoy outdoor recreation on Canada's forests and associated wildlands. By learning more about basic public needs and interests in outdoor recreation, foresters have an opportunity to improve their contributions in all aspects of forest resources use and management. We hope that greatly expanded studies in forest recreation management will be initiated soon for the major forest regions of Canada. We also would like to see careful assessments of the impact and tolerance of people on people as a major part of the psychological component of recreation carrying capacity. There is much need for increased support of many aspects of recreation research by Federal and Provincial Governments.

\section{Acknowledgements}

Reviews by R. H. Ahrens, K. Apt, A. Byrne, P. J. Dooling, H. K. Eidsvik, and D. Haley were very helpful. Financial support of the National and Historic Parks Branch of the Canadian Parks Service, and the University of British Columbia Committee on Research, and the cooperation of the Parks Branch of the B.C. Department of Recreation and Conservation were much appreciated. 


\section{References}

ADAMOVICH, L. 1971. Geometric standards of forest roads: an aesthetic view. Univ. B.C., Fac. Forest. Mimeo. 13 p.

APT, K. J. S. 1968. Preferences of mountain park visitors regarding some British Columbia and Alberta forest habitats. Univ. B.C., Fac. Forest., M. F. Thesis. 54 p.

APT, K. and J. H. G. SMITH. 1967. Survey of visitor preferences regarding forest habitat in some mountain parks of British Columbia and Alberta. Univ. B.C., Fac. Forest., Mimeo. 26 p.

BUREAU OF OUTDOOR RECREATION. 1967. Outdoor recreation space standards. Dep. Inter., Wash., D.C. 67 p.

BUREAU OF OUTDOOR RECREATION. 1970. Outdoor recreation research, 1969. Dep. Inter., Wash., D.C. 103 p.

DEPARTMENT OF RECREATION AND CONSERVATION. 1970. Annual report for 1969. Legislative Buildings, Vic toria, B.C.

DE VOS, A. and R. H. BAILEY. 1970. The effect of logging and intensive camping on vegetation in Riding Mountain National Park. Forest. Chron. 46: 49-55.

DOUGLASS, R. W. 1969. Forest recreation. Pergamon Press. $355 \mathrm{p}$.

DOOLING, P. J. 1969a. Development of a full range of outdoor recreation services and opportunities in Western Canada. Univ. B.C., Fac. Forest., Mimeo. 20 p. (Also in B.C. Soil Science Workshop Rep. No. 4: 66-80.)

DOOLING, P. J. 1969b. Soils, carrying capacity, and resource-based recreation services. Univ. B.C., Fac. Forest. Mimeo. 10 p.

FORD-ROBERTSON, F. C. (Ed.) 1971. Terminology of forest science technology, practice and products. Society of American Foresters, Wash. D.C. 349 p.
FRADKIN, P. and W. ENDICOTT. 1969. Population mass destroying U.S. parks. Vancouver Sun, July 18, p. 34.

GILBERT, D. L. 1971. Natural resources and public relations. The Wildlife Society, Wash., D.C. 320 p.

KISSICK, N. L. 1969. Research required for the development of a full range of recreational opportunities and services in eastern Canada. Univ. N. B., Fac. Forest., Mimeo. 8 p.

LITTLEJOHN, B. M. and D. H. PIMLOTT. (Eds.) 1971. Why wilderness. New Press. 108 p.

MARSHALL, H. 1971. People's needs and expectations: recreation. Proc. 1970 Western Forestry and Conservation Assoc., Ecology, Economics, and the Forest Environment: 24-26.

MATTHEWS, J. R. 1971. An investigation of sound attenuation by tree stands. Univ. B.C., Fac. Forest, M. F. thesis. $160 \mathrm{p}$.

PIMLOTT, D. H., C. J. KERSWILL and J. R. BIDER. 1971. Scientific activities in fisheries and wildlife resources. Science Council of Canada. Special Study No. 15, Ottawa. 191 p.

SCIENCE COUNCIL OF CANADA. 1970. Seeing the forest and the trees. Rep. No. 8. Ottawa. 22 p.

SMITH, J. H. G. 1969. Improved management is needed to preserve the beauty of our landscapes and expand outdoor recreation opportunities. Univ. B.C., Fac. Forest., Mimeo. 5 p.

SMITH, J. H. G. and G. LESSARD. 1971. Forest resources research in Canada. Science Council of Canada, Special Study No. 14, Ottawa. 204 p.

THE SUN. 1971. Public campsites are deteriorating. (Editorial.) Aug. 10, p. 4.

TRAVELLER. 1971. What's news outdoors? Our deteriorating campsite system. B.C. Outdoors 27 (4): 12-13.

Do you have copies of these publications by the Canadian Institute of Forestry / Institut forestier du Canada? If not, you are missing out on some very useful information. Copies may be obtained by writing to: The Canadian Institute of Forestry, Box 5000, Macdonald College, Quebec.

\section{Forestry Education in Canada}

This 400-page book is the result of extensive study by Dr. G. A. Garratt, Dean Emeritus, Yale University School of Forestry, conducted at the request of the Canadian Institute of Forestry. The study examines Canadian education in forestry and related fields; in particular it -

- reviews the development of professional education since its inception in 1907

- assesses the current status of education and associated research

- sets goals for professional and technical education during the next 10 to 20 years

\section{The Forestry Chronicle Cumulative Index}

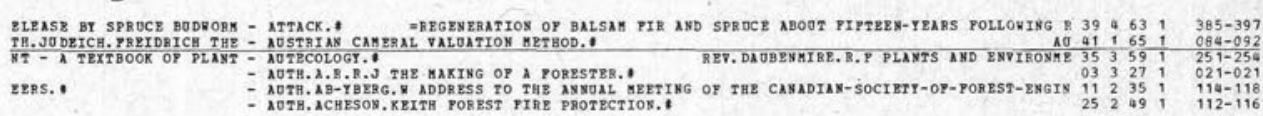

The contents of the first 44 volumes of The Forestry Chronicle are here in the form of a cumulative keyword and cumulative table of contents. 